Undas Vol 12. , Nomor 1, Juni $2016: 87--96$

\title{
NILAI-NILAI PENDIDIKAN KARAKTER DALAM DANG-IDANG MASYARAKAT KAYU AGUNG
}

\author{
Values of Character Education \\ Dang-Idang in Kayu Agung Community \\ Yeni Mastuti \\ Balai Bahasa Sumatera Selatan \\ Pos-el: yeni.mastuti@yahoo.co.id
}

\begin{abstract}
Abstrak: Tujuan Penelitian ini untuk mengidentifikasi dan mendeskripsikan pendidikan karakter yang terdapat dalam sastra tutur dang-idang. Masalah dalam penelitian ini adalah pendidikan karakter apa sajakah yang terdapat dalam sastra tutur dang-idang. Adapun metode yang digunakan dalam penelitian ini adalah metode deskriptif. Sedangkan data yang dianalisis menggunakan pendekatan sosiologi sastra. Objek penelitian ini adalah tradisi lisan dang-idang yang dituturkan oleh masyarakat yang tinggal di Kayu Agung, Sumatera Selatan. Nilai-nilai pendidikan karakter yang berhasil diidentifikasi oleh penulis dalam penelitian ini adalah religius, kerja keras, tanggung jawab, mandiri, komunikatif, peduli sosial, dan peduli lingkungan.
\end{abstract}

Kata kunci: Pendidikan karakter, sastra tutur, dang-idang

Abstract: This study aims to identifie and describe character education contained in the traditional literature of dang-idang. This study focusses of character what are contained in the traditional literature of dang-idang. As for the methods used in this research is descriptive method. While the data were analyzed using sociological approach to literature. The object of this study is the traditional literature of dang-idang by people who live in Kayu Agung, South Sumatra. The values of character education were identified by the authors in this study is a religious, hard work, responsibility, independent, communicative, social care, and care for the environment.

Key words: Character education, the traditional literature, pendekatan ideologi sastra.

\section{PENDAHULUAN}

Di era globalisasi saat ini fenomena degradasi moral kerap bermunculan. Perilaku amoral yang melibatkan remaja sebagai pelakunya semakin meningkat, seperti tawuran dan tindak kekerasan, narkoba dan miras, juga pergaulan bebas. Nampaknya hal tersebut diiringi pula dengan minat terhadap sastra yang juga mengalami degradasi. Hal ini disebabkan oleh tuntutan jaman yang serba instan dan serba cepat. Tontonan yang tanpa kita sadari masuk melalui televisi di rumah kita sendiri dimulai kartun untuk anak-anak didominasi oleh film katrun dari luar negeri seperti Naruto, Spongebob, Dora the Explorer, dan sebagainya. Sinetron-sinetron dari India setia menemani baik pagi, siang, maupun malam, ada juga sinetron produksi negeri sendiri yang bercerita tentang putri duyung yang aduhai hingga kehidupan anak jalanan yang penuh kekerasan. Tradisi mendongeng untuk peninabobokan anak sebagai pengantar tidur 
cukup digantikan dengan menonton tivi secara berjamaah.

Untuk mewujudkan generasi masa depan yang cerdas, baik secara intelektual, emosional, spiritual, maupun sosial perlu ada upaya serius dari segenap komponen bangsa untuk membangun "kesadaran kolektif" demi mengembalikan karakter bangsa yang hilang. Salah satu upaya tersebut adalah dengan kembali ke dunia sastra yang keindahannya dapat memperkaya wawasan dan daya nalar. Sastra mengajarkan nilai-nilai luhur kemanusiaan kepada pembacapendengarnya dan memberikan pencerahan. Dengan membaca dan memahami karya sastra, siswa mencoba memahami kehidupan, mencoba memperoleh nilai-nilai positif dan luhur dari kehidupan, dan pada akhirnya memperkaya batinnya.

Sebagai warisan budaya bangsa, sastra lisan yang terdapat di daerah Kayu Agung merupakan khazanah budaya masyarakat di masa lalu. Nilai-nilai yang terdapat di dalamnya itu penting diketahui. Dikatakan demikian bukan saja dalam rangka untuk memahami nilai-nilai budaya masyarakat lama itu sendiri, tetapi yang lebih penting, berguna bagi pemahaman terhadap nilai-nilai budaya masyarakat Indonesia modern yang pada dasarnya berpijak pada nilai-nilai budaya masyarakat tradisional.

Salah satu sastra lisan di daerah Kayu Agung adalah Dang Idang. Di dalam khazanah sastra Indonesia dang Idang termasuk dalam jenis puisi lama. Dang Idang adalah sejenis pantun yang dimiliki oleh penduduk di daerah Kayu Agung yang terdiri dari empat baris. Baris pertama dan kedua adalah sampiran, sedangkan baris ketiga dan keempat adalah isi. Dang Idang menggunakan rima $\mathrm{ab} a b$. Ada beberapa jenis Dang Idang, yakni untuk Dang Idang untuk menidurkan anak, Dang Idang bertepuk, dan Dang Idang anak-anak (permainan anak-anak).

Dang idang yang dilantunkan orang dewasa dilantunkan pada saat menidurkan anak atau membuay anak. Dilagukan dengan nada yang tenang dan terkadang diselingi dengan ucapan dzikir. Biasanya anak yang akan ditidurkan diletakkan dalam selembar kain yang dibentuk menjadi sebuah ayunan atau yang lebih dikenal dengan sebutan buayan. Anak tersebut diayun-ayunkan dalam buayan sambil diiringi dengan alunan lagu pantun dang idang.

Pada umumnya masyarakat Kayu Agung menidurkan anaknya di dalam rumah, sedangkan yang mengasuh anak bisa jadi orang tua kandungnya maupun orang yang dipercayakan orang tua si anak untuk mengasuh anak tersebut. Kegiatan membuay ini hingga sekarang masih dapat dilihat dalam kehidupan masyarakat Kayu Agung namun pengasuh yang dapat melantunkan dang idang untuk mengantar anak tidur sudah sangat jarang ditemukan. Pada saat penelitian dilangsungkan di daerah Kayu Agung, peneliti hanya menemukan dua orang ibu yang dapat menuturkan dang idang ini.

Dang-idang bertepuk dituturkan oleh pengasuh sambil bertepuk tangan. Si anak ikut juga bertepuk tangan melihat cara pengasuhnya. Kegiatan ini mereka lakukan saat anak terjaga atau sedang bermain-main. Suasana gembira mengiringi alunan dang-idang yang mereka bawakan. Kegiatan ini dapat disebut dengan permainan antara pengasuh dan anak yang diasuh. Dalam kegiatan ini selain melatih kata-kata untuk didengar si anak pengasuh pun melatih gerak tubuh anak yang diasuhnya. Dang idang bertepuk bisa dilakukan di mana saja, baik di dalam rumah, di halaman, maupun di jalan ketika pengasuh anak membawa anak yang diasuhnya berjalan-jalan. Kegiatan ini masih dapat ditemui walau hanya 
pada orang-orang tertentu saja dan dengan tidak manggunakan bahasa Kayu Agung secara keseluruhan.

Dang-idang Anak-anak khusus dituturkan oleh anak-anak, baik perorangan maupun secara bersama-sama pada saat mereka bermain. Dang-idang ini terbagi lagi menjadi tiga bagian, yaitu dang-idang untuk bermain pagar-pagaran, dang-idang untuk bermain menumpuk dan memijit belakang tangan dan dang-idang untuk mempermainkan ikan buntal. Melihat kenyataan di lapangan, peneliti tidak menemukan lagi dang idang jenis ini. Dang idang jenis ini tinggal menjadi cerita orang tua mereka saja, dan tidak semua orang tua mengetahui bahwa dang idang khusus untuk permainan anak ini pernah ada.

Isi atau pesan yang terdapat dalam Dang Idang tersebut sarat dengan nilai-nilai kearifan lokal masyarakat Kayu Agung yang dapat dijadikan sebagai dasar atau pedoman dalam berprilaku. Berdasarkan pada hal tersebut rumusan masalah dalam penelitian ini adalah nilai-nilai pendidikan karakter apa sajakah yang terdapat di dalam sastra tutur Dang Idang?

Penelitian ini bertujuan untuk mendeskripsikan nilai-nilai budaya yang terdapat dalam Dang Idang. Dari hasil pendeskripsian nilai-nilai budaya dalam Dang Idang ini, masyarakat umum dapat mengetahui bahwa dalam sastra lisan daerah Kayu Agung terdapat nilai-nilai yang berguna bagi kehidupan. Selain itu penelitian ini diharapkan bermanfaat untuk disumbangkan pada pengajaran sastra, yaitu sebagai pengetahuan bagi peminat di bidang sastra dan budaya serta dalam dunia pendidikan.

\section{KERANGKA TEORI}

Tulisan ini menggunakan pendekatan sosiologi sastra, yaitu penelitian yang terfokus pada masalah manusia. Hal berdasarkan pendapat bahwa sastra sering mengungkapkan perjuangan umat manusia dalam menentukan masa depannya berdasarkan imajinasi, perasaan, dan intuisi. Menurut Laurenson dan Swingewood (dalam Endraswara, 2008: 79) terdapat tiga perspektif berkaitan dengan sosiologi sastra, yaitu: (a) penelitian yang memandang karya sastra sebagai dokumen sosial yang di dalamnya merupakan refleksi situasi pada masa sastra tersebut diciptakan, (b) penelitian yang mengungkapkan sastra sebagai cermin situasi sosial penulisnya, dan (c) penelitian yang menangkap sastra sebagai manifestasi peristiwa sejarah dan keadaan sosial budaya.

Abrams (dalam Faruk, 1994:4), menyatakan bahwa "art is like a miror" menunjukkan bahwa karya sastra sebagai salah satu genre karya seni merupakan cerminan kehidupan sosial masyarakat tempat karya sastra tersebut diciptakan oleh pengarangnya. Hal tersebut senada dengan pernyataan Goldman (dalam Dharma, 2004:47) yang menyatakan bahwa sastra tidak dapat dipisahkan dari masyarakat. Hal senada juga diungkapkan oleh De Bonald (dalamWellek \& Warren, 2012: 110) menyatakan bahwa "sastra adalah ungkapan perasaan masyarakat" (literature is an expression of society). Secara singkat dapat dikatakan bahwa sastra lahir dari fenomena yang muncul dalam masyarakat dan melalui sastra fenomena sosial yang muncul di masyarakat diramu kembali dengan imajinasi dan kreativitas pengarang sehingga menjadi sesuatu yang memiliki nilai dulce et utile.

Secara singkat dapat juga dikatakan bahwa sastra lahir dari fenomena yang muncul dalam masyarakat dan melalui sastra fenomena sosial yang muncul di masyarakat diramu kembali dengan imajinasi dan kreativitas pengarang sehingga menjadi sesuatu yang memiliki nilai dulce et utile. Adapun berkaitan dengan sastra 
lisan, Djamaris (2005:2) menjelaskan sebagai berikut.

Sastra lisan dan sastra tertulis biasa disebut dengan istilah sastra rakyat atau sastra tradisional. Sastra rakyat (folk literature) adalah bagian dari bidang Ilmu Folklore, yaitu sastra yang hidup di kalangan rakyat, sastra milik bersama, milik rakyat, bukan milik individual, tanpa nama pengarang, yang biasa disebut dengan anonim. Sastra rakyat berkembang secara turun-temurun, dari satu generasi ke generasi berikutnya, dari anak kepada cucu, dan seterusnya.

Permainan bunyi, keteraturan irama, gaya bahasa, dan majas adalah beberapa kekuatan yang dimiliki oleh sastra lama, dalam hal ini adalah tradisi lisan, sehingga pendengar akan merasakan keindahan dan kenikmatan tuturan yang dituturkan oleh penutur. Melalui tuturan yang dituturkan inilah terkandung hal-hal yang memiliki sifat ajaran tentang moral, kebaikan yang senantiasa akan mengingatkan manusia untuk selalu 'eling' terhadap lingkungan yang ada di sekitarnya. Melalui tuturan inilah terjadi transformasi nilai-nilai moral dari generasi tua kepada generasi muda. Sudjiman menyatakan bahwa tradisi lisan mengandung sifat pengajaran, bimbingan moral, keteladanan, terutama tentang kearifan hidup, hidup bermasyarakat, dan kehidupan beragama (Sudjiman, 1994:14).

Karakter manusia tidak selamanya statis, karakter manusia dapat berubah karena adanya kemauan untuk belajar dan tekad membangun karakter yang baru. Tidak mudah memang membangun karakter yang baru, namun tidak ada ruginya belajar untuk menjadi lebih baik. Kementerian Pendidikan Nasional telah merumuskan 18 Nilai Karakter yang akan diharapkan dalam diri peserta didik sebagai upaya membangun karakter bangsa., yaitu: religius, jujur, toleransi, disiplin, kerja keras, keratif, mandiri, demokratis, rasa ingin tahu, semangat kebangsaan, cinta tanah air, menghargai prestasi, komunikatif, cinta damai, gemar membaca, peduli lingkungan, peduli sosial, tanggung jawab (http:/ / layananguru.blogspot.co.id/2013/05/18-nilai-dalam pendidikan- karakter.html)

\section{METODE PENELITIAN}

Penelitian ini menggunakan metode deskriptif. Maksudnya, penelitian ini dilakukan seobjektif mungkin, didasarkan semata-mata pada data yang ada pada masa sekarang. Walaupun demikian, bahan penelitian yang akan dipilih dari data yang terkumpul sesuai dengan tujuan penelitian.

Setelah data terkumpul kemudian diolah dengan menggunakan teknik analisis data, khususnya analisis tematik (thematic analysis). Teknik analisis tematik adalah suatu teknik untuk mengungkapkan tema budaya. Langkah-langkah analisis tematik, yaitu: membaca secara cermat keseluruhan data lapangan, memberikan kode-kode pada topik yang sesuai dengan tujuan penelitian, menyusun tipologi, dan membaca kepustakaan yang terkait dengan masalah dan konteks.

\section{ANALISIS DAN PEMBAHASAN}

Kemajuan teknologi memiliki peranan yang sangat besar dalam mengubah berbagai aspek kehidupan masyarakat Kayu Agung. Misalnya, kemajuan teknologi di bidang informasi dan komunikasi menyuguhkan berbagai alternatif tontonan hiburan bagi masyarakat Kayu Agung. Tanpa disadari lambat laun hal ini mengakibatkan terjadinya pergeseran 
konsumsi budaya dan seni tradisional yang ada di masyarakat.

Kehadiran musik dangdut, organ tunggal berhasil menggeser kehadiran Dang idang di acara-acara hajatan yang diselenggarakan oleh masyarakat Kayu Agung. Hal inilah yang mengakibatkan Dang idang kurang digemari oleh generasi muda dan anak-anak.

Harus diakui bahwa arus deras mainan anak produksi luar negeri secara perlahan dan pasti telah mengeser kedudukan permainan tradisional anak yang penuh dengan nilai-nilai keraifan lokal yang dapat diajdikan sebagai benteng budaya. Kehadiran Game on line dan Play Station berhasil menggeser kehadiran Dang idang Anak yang menjadi permainan anak-anak Kayu Agung. Games on Line dan Play Station menyuguhkan hal-hal yang mampu menarik perhatian dan minat anak-anak untuk mengeluti permainan ini. Hal ini diperparah dengan kebanggaan dari orang tua terhadap anak-anaknya yang mengenal teknologi. Secara perlahan dan pasti hal ini mengakibatkan Dang idang Anak kurang digemari oleh anakanak. Akibatnya untuk mencari seseorang yang memiliki keahlian untuk membawakan tuturan Dang idang dan Dang idang Anak bagaikan mencari jarum di tumpukkan jerami.

Berikut ini adalah contoh dang-idang dan pembahasan mengenai nilai-nilai pendidikan karakter yang terdapat dalam dang-idang tersebut.

\section{a. Karakter Religius}

nyak abe kinjak libe

saya berjalan hilir mudik

nyangkim kulat gerigit membawa jamur gerigit bakaskune kok tuhe kakekku sudah tua semboyang di mesigit sholat di masjid

Pada sampiran, 'nyak abe kinjak libe' (saya berjalan hilir mudik) dan 'nyangkim kulat gerigit' (membawa jamur gerigit) menggambarkan kegiatan si pelantun yang sibuk dengan urusan duniawinya, terutama untuk memenuhi kebutuhan hidup. Dikatakan bahwa ia hilir mudik membawa jamur gerigit. Mungkin untuk dijualnya dan mungkin pula ia mencari ke sana ke mari sebagai lauk teman nasi keluarganya.

Dalam isi, 'bakaskune kok tuhe' (kakekku sudah tua) dan 'semboyang di mesigit' (sholat di masjid) dilanjutkan dengan penggambaran tokoh kakeknya yang sudah tua melakukan sholat di masjid. Ini bukan hanya sebuah gambaran tapi boleh jadi merupakan sebuah himbauan kepada orang tua untuk ingat dengan ahirat. untaian dang idang ini menunjukkan sebuah karakter religius yang selayaknya diperlihatkan orang tua.

Dang-idang berikut juga menunjukkan karakter religius.

mesigit hatop ringgit masjid beratap

$\begin{array}{ll} & \text { ringgit } \\ \text { ban siban hatop ban } & \text { ban siban atap ban }\end{array}$ ban

sayid bumi nyak langit tinggi bumi dari

langit

Tuhan podaw Tuhan pemilik timbangan timbangan

Dalam sampiran terdapat persamaan bunyi yang tujuannya untuk mencocokkan ujung kalimat pada sampiran dan isi, yakni ringgit dan langit serta ban-ban dan timbangan, yaitu 'mesigit hatop ringgit' (masjid beratap ringgit) dan 'ban siban hatop ban 
ban' (ban siban atap ban ban). Pemilihan ringgit dapat merupakan simbol bahwa atap masjid yang merupakan tempat ummat Muslim beribadah adalah tempat yang berharga, bukan dibuat asal jadi dan sembarangat, atapnya saja terbuat dari kumpulan uang (ringgit adalah uang/alat pembayaran yang syah pada zaman dahulu di daerah Kayu Agung).

Bagian isi, 'sayid bumi nyak langit' (tinggi bumi dari langit) dan 'Tuhan podaw timbangan (Tuhan pemilik timbangan) mengemukakan tentang kebesaran Tuhan yang merupakan pemilik seluruh kekuasaan. Kita sebagai manusia yang lemah tak berdaya hendaknya selalu memuliakan Tuhan dengan menanamkan pada diri untuk patuh kepada perintah Tuhan pemilik semesta alam ini dan menjauhi semua larangannya. Makna pemilik timbangan adalah penguasa dan penentu hidup manusia. Tuhan yang Maha Adil serata Maha Bijaksana.

\section{b. Karakter Kerja Keras}

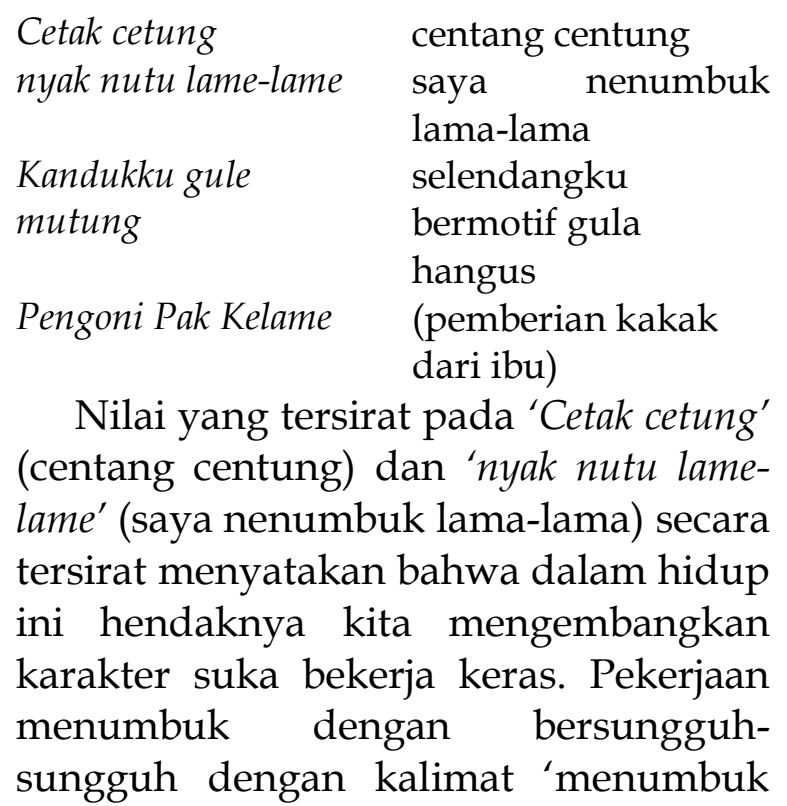

lama-lama', berarti begitu bahan untuk ditumbuk yang harus dilakukannya. Pekerjaan ini bukanlah pekerjaan yang mudah, selain tenaga yang prima, ketelitian pun dibutuhkan agar mendapatkan hasil yang memadai.

Pada isi, 'Kandukku gule mutung' (selendangku bermotif gula hangus) dan 'Pengoni Pak Kelame' (pemberian kakak dari ibu) menceritakan bahwa selendang yang dipakainya adalah pemberian Pak Kelama (kakak dari ibu). Ia nampaknya sangat bersuka cita dengan pemberian selendang dari Pak Kelamanya itu sehingga ia menggoda Pak Kelama dengan kalimat humornya. Dalam sampiran dipertanyakan Pak Kelama yang mana yang memberinya selendang. Hal ini terjawab dalam isi yang mengatakan bahwa Pak Kelama yang sudah sangat tua, ini terlihat dengan gambaran bahwa rambutnya sudah tidak rata alias sudah menipis dan ubannya pun sudah memenuhi rambut tersebut.

\section{c. Karakter Tanggung Jawab}

$\begin{array}{ll}\text { Tanyut niku poti } & \begin{array}{l}\text { Terhanyut engkau } \\ \text { peti } \\ \text { di pemandian kepala } \\ \text { desa }\end{array} \\ \text { tumpak buayan riye } & \begin{array}{l}\text { alangkah susah pak } \\ \text { depati } \\ \text { alang susah depati }\end{array} \\ \text { ge mancang morge } & \begin{array}{l}\text { Marga Sembilihan di } \\ \text { siwe }\end{array} \\ & \text { ibu) }\end{array}$

Kalimat pada sampiran yang menyatakan 'Tanyut niku poti' (terhanyut engkau peti) dan 'tumpak buayan riye' (singgah di pemandian kepala desa) mengingatkan bahwa jangan sampai 
calon pemegang kekuasaan terbawa nafsu untuk meraih kekuasaan. Alangkah mulianya jika ia mempunya tujuan yang jelas, yakni akan membawa rakyatnya kepada kemakmuran dan kebahagiaan dunia ahirat. Makna terhanyut sama dengan mencelakakan diri sendiri. Bukankah setiap amanah akan diminta pertanggungjawaban baik di dunia maupun di ahirat kelak? Makna dalam dang idang ini mengajarkan kepada kita untuk dapat bertanggung jawab dengan mengendalikan hawa nafsu terutama nafsu duniawi sehingga kita tidak tersesat dan dapat meraih bahagian dunia akhirat.

Isi pantun ini, 'alang susah depati' (alangkah susah pak depati) dan 'ge mancang morge siwe' (akan pemilihan di Marga Sembilan/Kayu Agung) merupakan sindiran kepada para calon pemegang kekuasaan. Biasanya seseorang yang menginginkan kekuasaan berada di tangannya akan berusaha sekuat mungkin dan berdaya upaya agar kekuasaan tersebut dapat diraihnya. Selanjutnya bila ia telah mendapatkan kekuasaan itu maka ia akan berusaha pula sepenuh hati agar jangan terlepas atau berpindah tangan kepada orang lain. Begitu risau hatinya bila ia nanti tidak dapat mempertahankan kekuasaan yang sudah berada di tangangannya tersebut.

\section{d. Karakter Mandiri}

sekali ruwe mosi segunggung rik selake

hamotko hayi-hayi kemarau diterime sekali dua kali berpakaian mas dan perak tak kusangka-sangka kemarau pun diterima
Pada sampiran, 'sekali ruwe mosi' (sekali dua kali) dan 'segunggung rik selake' (berpakaian mas dan perak). Dalam perjalanan kehidupan terkadang kita mendapatkan rezeki berupa materi dalam jumlah yang banyak, dalam sampiran diumpamakan berpakaian mas dan perak. Mas adalah logam mulia yang bernilai tinggi dan perak pun termasuk perhiasan yang cukup bernilai. Dalam kebiasaan daerah ini pakaian (perhiasan) menunjukkan status sosial. Orang yang memakai emas dapat digolongkan sebagai golongan berada (berpenghasilan lebih tinggi), berperhiasan perak pun termasuk golongan yang cukup berada (biasanya perak yang berwarna putih akan disepuh (diwarnai) seperti warna emas, sehingga nampak seperti memakai emas. Kemilau emas yang bersinar gemilang mengisyaratkan kabahagiaan, kemakmuran, kesuksesan maupun kecukupan.

Pada isi, 'hamotko hayi-hayi' (tak kusangka-sangka) dan 'kemarau diterime' (kemarau pun diterima) menasihatkan bahwa perjalanan kehidupan tidak selalu berpihak kepada kita, terkadang kita mendapat kebahagiaan terkadang pula mendapat kesusahan. Dalam isi perumpamaan kemarau identik dengan gersang, tandus, kering, atau panas, yang kesemuanya merujuk pada kekurangan. Kurang di sini dapat berupa kekurangan dalam segi material maupun spiriitual. Namun semua itu harus diterima dengan lapang dada dengan selalu berusaha dan berdoa. Sikap mandiri harus kita miliki agar terhindar dari kesusahan hidup yang berkepanjangan. 
Dang-idang berikut juga memiliki pesan untuk hidup mandiri yang lebih dikhususkan kepada pemuda yang sudah cukup umur dan hendak mencari pasangan hidup namun belum punya penghasilan.

$\begin{array}{ll}\text { Kedakduk kedakduk } & \begin{array}{l}\text { entah ada entah } \\ \text { tiada } \\ \text { buah kayu } \\ \text { bujangan dari sungai } \\ \text { muanay sungai Topuk } \\ \text { Topuk } \\ \text { mannyorte Karang Sie } \\ \text { bertandang ke } \\ \text { Karang Sie } \\ \text { membawakan ikan } \\ \text { tapah busuk } \\ \text { ampayne nanas ngure } \\ \text { sayurnya nanas } \\ \text { muda }\end{array}\end{array}$

laju turun te biduk terus turun dari perahu

dehoji-hoji kowe dipermain-mainkan

kera

kowene cumeruguk keranya duduk duduk

labuhe haguk dipe berlabuhnya ke arah mana

Ini merupakan lelucon namun secara tersirat ada makna sentilan kepada pemuda bila ingin mendekati lawan jenis setidaknya memiliki penghasilan yang memadai. Jika untuk menghidupi diri sendiri saja tidak sanggup sebaiknya tunda dulu untuk berkeluarga. Jika ingin hidup layak seperti orang lain maka berusahalah dengan giat, tidak hanya bersantaisantai.

\section{e. Karakter Komunikatif}

Bunge timpok bunga di sawah
Mokarne sarat dobi mekarnya di sore hari

Adik batin tekojut adik kaya mendadak Mak nyambat sikam lagi (bila) bertemu tak menegur kami lagi

Sebagai manusia yang merupakan ciptaan Tuhan dan memiliki banyak kekurangan tidak selayaknya kita bersikap sombong. Tak ada manusia yang sempurna di muka bumi ini karena kesempurnaan hanyalah milik Sang Pencipta. Sikap sombong hanya akan merendahkan derajat manusia. Kekayaan, kecantikan/ketampanan, kedudukan, kecerdikan, dan kelebihan yang lainnya hanyalah sementara, ia akan hilang bila Tuhan telah mencabut tersebut.

\section{f. Karakter Peduli Sosial}

De mundu de mundu mengkudu2x bertali sabuk handak putih

Pakgulu mangsemaju pak gulu (kk dr ayah) dpt mantu

Pukalkon juge onyak ikutkan juga saya bekerja

Nyak hage pukal tasak saya ingin bagian memasak

Majune kok setuju pengantinnya sudah setuju

Ge mongan omi handak mau makan nasi putih

Onyi gulai nok maju apakah gulai sang pengantin

Kulob-kulobkon itak rebus-rebuskan kacang

Itak nyak mare baru kacang dari Muara Baru Punyo nyak mare lobak milikku dari Muara Lebak 
Singgah de Tobing

Paku

Nyak mone ngumpe

tipak

Kawaikune beludru

Bolitkune becurak

kainku berwarna

Curakne curak mundu

Curak selake masak bajuku dari (bahan)

beludru

warni

singgah ke Tebing

Paku

saya yang pertama

memegang tepak

gambarnya gambar

mengkudu

gambar perak

bersepuh emas

Sikap suka menolong terlihat jelas dalam syair ini. Dalam kehidupan adat masyarakat Kayu Agung, bila ada hajatan maka mereka akan suka rela membantu pemilik hajatan. Hal ini masih dapat dilihat hingga saat ini. Pekerjaan yang semula berat akan menjadi ringan dan persaudaraan pun semakin erat.

\section{g. Karakter Peduli Lingkungan}

$\begin{array}{ll}\begin{array}{l}\text { ayun, ayunlah lambun } \\ \text { ayun anaq rEgasE }\end{array} & \begin{array}{l}\text { ayun, ayunlah cepat } \\ \text { ayun anak } \\ \text { kesayangan } \\ \text { tempatmu selendang } \\ \text { timbuqmu komban } \\ \text { ayun } \\ \text { pEngsalinanmu connE }\end{array} \\ \begin{array}{l}\text { penukar pakaian } \\ \text { indah' }\end{array} \\ \begin{array}{ll}\text { connEmu lawE-lawE } & \begin{array}{l}\text { 'sayangku diam- } \\ \text { diam } \\ \text { pakaian anak ogan } \\ \text { pakaian sanaq ogan } \\ \text { Patang ari wai musi }\end{array} \\ \begin{array}{l}\text { sungai air musi } \\ \text { Pujan }\end{array} & \begin{array}{l}\text { Palembang banjir } \\ \text { karena hujan' }\end{array} \\ \text { tak cetung, taklah } & \text { 'tak bumbum, taklah } \\ \text { cetng } & \text { bumbum } \\ \text { nyaq niku lamE-lamE } & \begin{array}{l}\text { dengan } \\ \text { lama-lama }\end{array}\end{array}\end{array}$

$\begin{array}{ll}\text { bEjojolah lElutung } & \begin{array}{l}\text { berdesakanlah } \\ \text { lelutung } \\ \text { pemberian pak } \\ \text { Kelame' }\end{array}\end{array}$

La Illaha Ilallaho ‘Laa Ilaaha ilallah

Muhammad Muhammad

rosullullah rosullullah'

Dang-idang ini dituturkan untuk menidurkan anak, agar si anak cepat tertidur. Pengasuh pada umumnya menidurkan anak dalam buaian atau ayunan sambil mendendangkan dangidang tersebut. Isi yang tersirat adalah rasa kasih sayang sang pengasuh pada anak asuhnya. Ini pun diiringi dengan harapan semoga anak tersebut menjadi anak yang dapat dibanggakan keluarga. Tak lupa diiringi dengan kalimat zikir agar telinga sang anak sudah terbiasa sejak kecil mendengar kalimat-kalimat tauhid. Inipun mengandung harapan agar pada akhirnya anak tersebut dapat menjadi anak soleh.

\section{PENUTUP}

Dari uraian yang telah dipaparkan, disimpulkan bahwa ada beberapa pendidikan karakter dalam tradisi lisan dang-idang. Nilai-nilai pendidikan karaakter yang berhasil diidentifikasi noleh penulis adalah: religius, kerja keras, mandiri, peduli lingkungan, peduli sosial, dan tanggung jawab.

Dengan adanya nilai-nilai pendidikan karakter tersebut tentu saja setidak-tidaknya akan tumbuhsifat arif dan bijaksana dalam mengelola dirinya, mengelola kehidupan komunitasnya, dan mengelola alam yang telah menyediakan semua kebutuhan hidup manusia. Nilai-nilai pendidikan karakter itu dapat dijadikan sebagai dasar pijakan untuk memberikan ajaran dan 
pengetahuan yang dapat menciptakan hubungan yang harmonis antara Tuhan, manusia, dan makhluk lainnya yang ada di bumi ini. Sastra tutur sebagai wahana efektif pengembangan pendidikan karakter. pelajaran sastra klasik merupakan wahana efektif bagi pengembangan karakter siswa. Dalam sastra tutur terdapat unsur budaya, sejarah, bahkan unsur ideologi di samping aspek emosional, intelektual, sosial, dan moralitas. Unsur-unsur itu pula yang selama ini merupakan bidang kajian dalam pengembangan kepribadian..
Sastra tutur dapat membantu pembentukan karakter siswa, melalui irama yang menyentuh juga pilihan kata yang menggugah sehingga siswa dapat memperoleh kesadaran, tanpa merasa dipaksa dan digurui. Untuk itu, pembelajarannya tidak cukup apabila berkutat pada soal teori. Ada aspek lain yang yang lebih penting, yaitu apresiasi dan kreasi. Kedua aspek tersebut bisa memberikan pengalaman dan kepribadian bersastra, terutama di dalam pembentukan karakter-karakter tertentu pada diri siswa.

\section{DAFTAR PUSTAKA}

Budiningsih, Asri. 2013. Pembelajaran Moral. Jakarta: Rineke Cipta.

Damayanti, Deni. 2014. Panduan Implementasi Pendidikan Karakter di Sekolah. Yogyakarta: Alaska.

Darma, Budi. 2004. Pengantar Teori Sastra. Jakarta: Pusat Bahasa. Jakarta: Yogjakarta: Pustaka Pelajar

Djamaris, Edwar. 2005. Diktat Bahan Penyuluhan Penataran sastra bagi Staf Peneliti Sastra Balai Bahasa Palembang. Jakarta.

Endraswara, Suwardi. 2003. Metodologi Penelitian Sastra. Yogyakarta: MedPress.

Faruk. 1999. Pengantar Sosiologi Sastra. Jogyakarta: Pustaka Pelajar.

Koesoema, Doni.. 2015. PendidikanKarakter Utuh dan Menyeluruh. Yogyakarta: Kanisius.

Sudjiman, Panuti. 1994. Filologi Meayu. Jakarta: Pustaka Jaya.

Suparno, Paul, S.J. 2015. Pendidikan Karakter di Sekolah. Yogyakarta: Kanisius.

Wellek dan Warren. 2012. Teori Kesusastraan. Jakarta: Gramedia.

http:/ /layanan-guru.blogspot.co.id/2013/05/18-nilai-dalam-pendidikan-karakter.html. 